\title{
SOLAR TREE - A SUSTAINABLE ENERGY APPROACH FOR FARMERS
}

\author{
Mukesh Kumar ${ }^{1}$, Lokesh Rana ${ }^{2}$, Amruta Pattnaik ${ }^{3}$ \\ ${ }^{1}$ Department of Physics, SSNC, University of Delhi, Alipur, Delhi, INDIA \\ ${ }^{2}$ Physics Department, ZakirHusainDelhi College, University of Delhi, Delhi, INDIA \\ ${ }^{3}$ Assistant Professor(EEE), ADGITM ,Delhi -110053, INDIA \\ *E-mail of the corresponding author: physics.ssn@gmail.com and OCHID ID 0000-0003-2570-1535
}

\begin{abstract}
The energy-producing similarity between the photoelectric effect and photosynthesis makes them more important for humans and has a large environmental impact potential. Sunlight is common in both and its longevity makes them an important solution tool for many human issues. The energy need is one of the important ones. The various researches are going on such sunlight energy conversions, various techniques like Photo Voltaic (PV), Solar Thermal (ST), Solar Photovoltaic-thermal (PV/T) conversion are proposed. Researchers are also not able to achieve $100 \%$ accuracy due to optical loss, thermal loss Recombination, Spectrum losses, and Impedance matching. Despite all these, it is found solar energy is a sustainable energy solution with the highest input capital, but with long durability, lower operational cost, and maintenance. The idea of the solar flexible trees is fit for meeting farmers' energy demands as well as makes them energy producers. This not only creates another source of income for them but also helps in farming. Besides suggesting, this work also addresses the difficulties engaged with this design model and also proposes future research scope. The tighter coupling of land use and management and energy generator ensure us for farmer's sustainable energy solution.
\end{abstract}

Keywords —Solar Energy, Energy, Farmer Income, Agriculture Sustainability

\section{INTRODUCTION}

Our country is known for its rural population and its agriculture. Agriculture products are considered as a divine gift of Mother Nature. Such agriculture productions require a lot of human hard works and other energy inputs. The energy requirement in the agriculture sector can be understood through a ladder approach and three levels are classified [1]. The primary energy input to agriculture is basic human energy which is used for cultivation, harvest processing without any external fuel source. The next level of energy utilization is in the form of energy from other living animals or natural resources $[12,15]$. The application of fuel-based energy technologies to agriculture is considered at the last level and most important for processing agricultural products. The poor people generally use rural energy for basic survival in cooking, lighting, domestic and community facilities. They also utilize traditional biomass fuels, fossil fuels, and electricity, if available. Humans depend on plants as a source of energy and plants depend on Sun to produce food.

Agriculture is both a producer and a consumer of energy. Now agriculture is like other businesses, expanding due to huge demands for food materials, but have certain ecological limitations. The perishable nature of agriculture output has increased the energy consumption in crop production, processing, packaging, and distribution process. The recent growth of industrial raw materials, food supply make agriculture-supported biomass energy becomes insufficient, and changes early 1900s energy sources use patterns that were mostly derived from agricultural products. Additionally, interest in energy production 
from agriculture products or by-products is also enhanced in energy markets. Various work has been done to find different ways to harvest energy from agricultural production and wastes, such as biofuel, biogas, combustion, gasification, and pyrolysis [16]. The quantum of energy produced through such techniques is not sufficient to meet agro-energy demands and also degrade the environment.

Recent development has shown solar energy is a clean and sustainable energy solution. It has vast potential to meet our all energy demands, including agricultural ones. Solar energy is a vital component for photosynthesis and solar energy generations [4,5,7]. This work explores how solar energy can be utilized to meet agri-energy demands, keeping because of land limitations. This work utilized the concept of the solar tree to meet such requirements. Thereafter it also discusses the basic layout for maximum efficiency. It also offers new frontiers and modifications to facilitate the process of reducing the present large agri-energy gap. There are some issues and concerns associated with the energy supplied to the farmers from the grid. Issues include high energy cost, cut-off due to high industry or domestic demands, etc.

\section{FARMING ENERGY-RELATED PROBLEM}

The pattern of energy use in agriculture has changed significantly worldwide. The rapid use of agricultural mechanization causes this shift. In Indian agriculture, the energy consumption structure also significantly changed, shifting from animal and human power to machinery, diesel, and now electricity. This steady increase, together with increased demand and marketing in agriculture. This shows a direct and robust relationship between energy use and agriculture. The increasing food grain demands have commercialized agriculture, which in turn increases agriculture mechanization. The storing, processing process, etc has increased the demands of electric energy in agriculture,

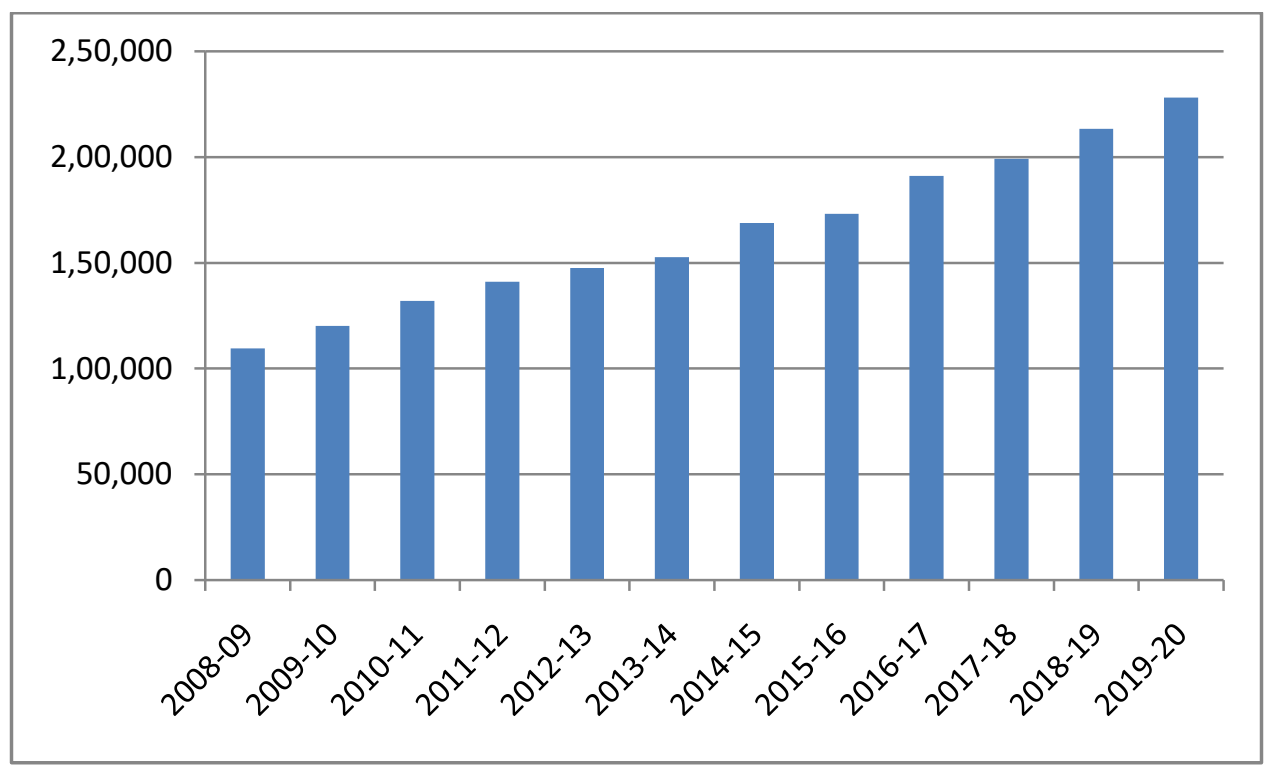

Figure 1: Indian- Agriculture Electric Energy use ( Giga Watt-hour) $[2,3]$ 
Through analysis of agriculture electricity, energy use pattern in India from 2008-09 to 2019-20 show a continuously increasing trend. An increase of 1,18,562 Giga watt-hour over 12 years [6]. This is projected to be 3,05,346 GWh if agricultural electric demand grows at 6 percent in the next 5 years. This projection is because of agriculture's gross domestic product (GDP) analysis. This is a huge energy demand, needs to be tackled, otherwise, food grain problems arise.

Electricity is also a necessary commodity for other sectors like Industry, domestic and commercial activates. Currently, for the financial year 2019-20, agriculture electric energy use in India is about 17.7 $\%$ of total electric energy production.

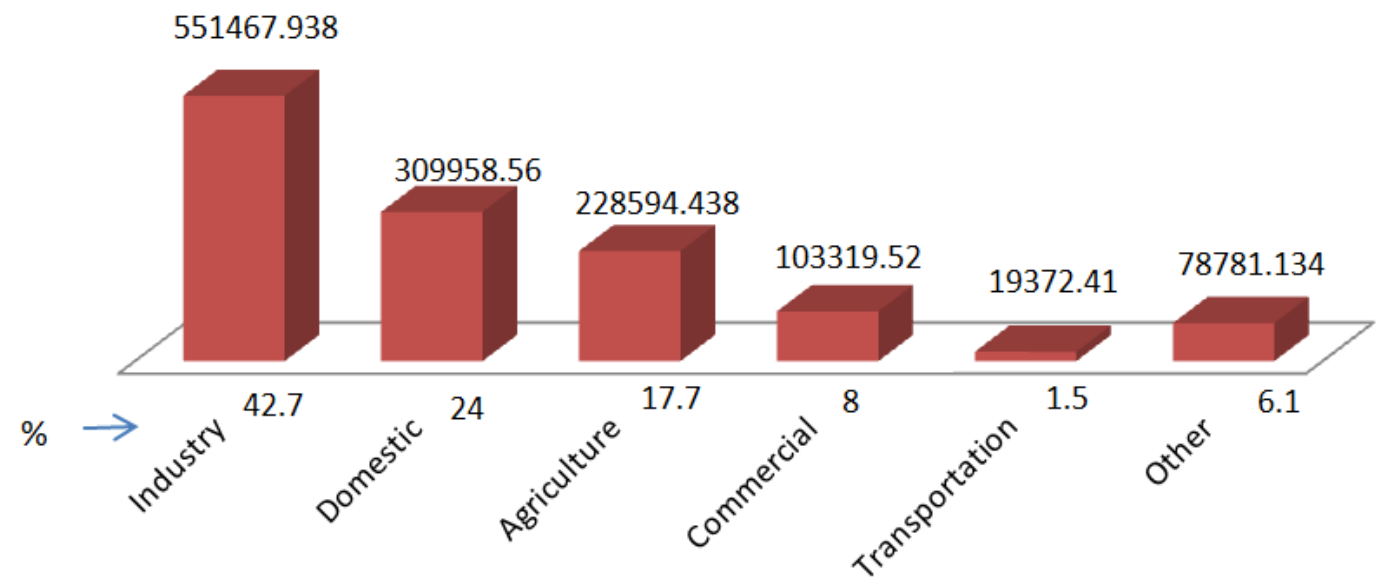

Figure 2: Electric Consumption (in GWh and in \%) [2,3]

Being agriculture, an energy producer, agriculture products such as Biofuel, biogas, biomass, charcoal, and plant oils, etc. can be used to meet out such an energy gap. Such extraction process is lengthy and releases a lot of non-environmental friendly gases. On other hand, fossil fuels can help in this regard, but they are also limited or produce environmental degradation. Although Biomass is considered a renewable one, a substitute for fossil fuel. But due to the low production ratio and associated environmental issues, one has to search for another alternative to meet such huge demands. Because of projected demand and source availability, solar energy can be a better substitute for such energy demands.

There is another alternative to meet such energy demands like population decrease, more agricultural land area. But such alternatives are not feasible and need to search for some good continuous energy supply source to avoid any food security issues.

\section{SOLAR ENERGY AN ULTIMATE ENERGY SOLUTION}

Sun in common in both Solar Energy \& Food Production. The various studies have found it a clean and ultimate energy source, low-cost energy solution without affecting the environment. Because of the sun's lifetime, it seems to be a sustainable energy solution with lots of agri-energy potential. India's unique geographical location shows tremendous potential for solar power generation. One study estimated energy potential of about $6000 \times 10^{6}$ Gigawatt per hour $(\mathrm{GWh})$ per year. Although the daily average global radiation varies from $2-7 \mathrm{kWh} / \mathrm{m}^{2}$ depending on the height from sea level and distance from the equator. 
Few studies claim that Solar Energy has solar potential and in previous years solar energy growth certifies the same. India has started its solar mission of achieving 100,00 MW solar energy by 2022. As per the study by Energy Statistics 2021 [6], the estimated potential of renewable power as of 31.03 .2020 is shown in fig 3 , and its shows that the major energy potential is a solar one.

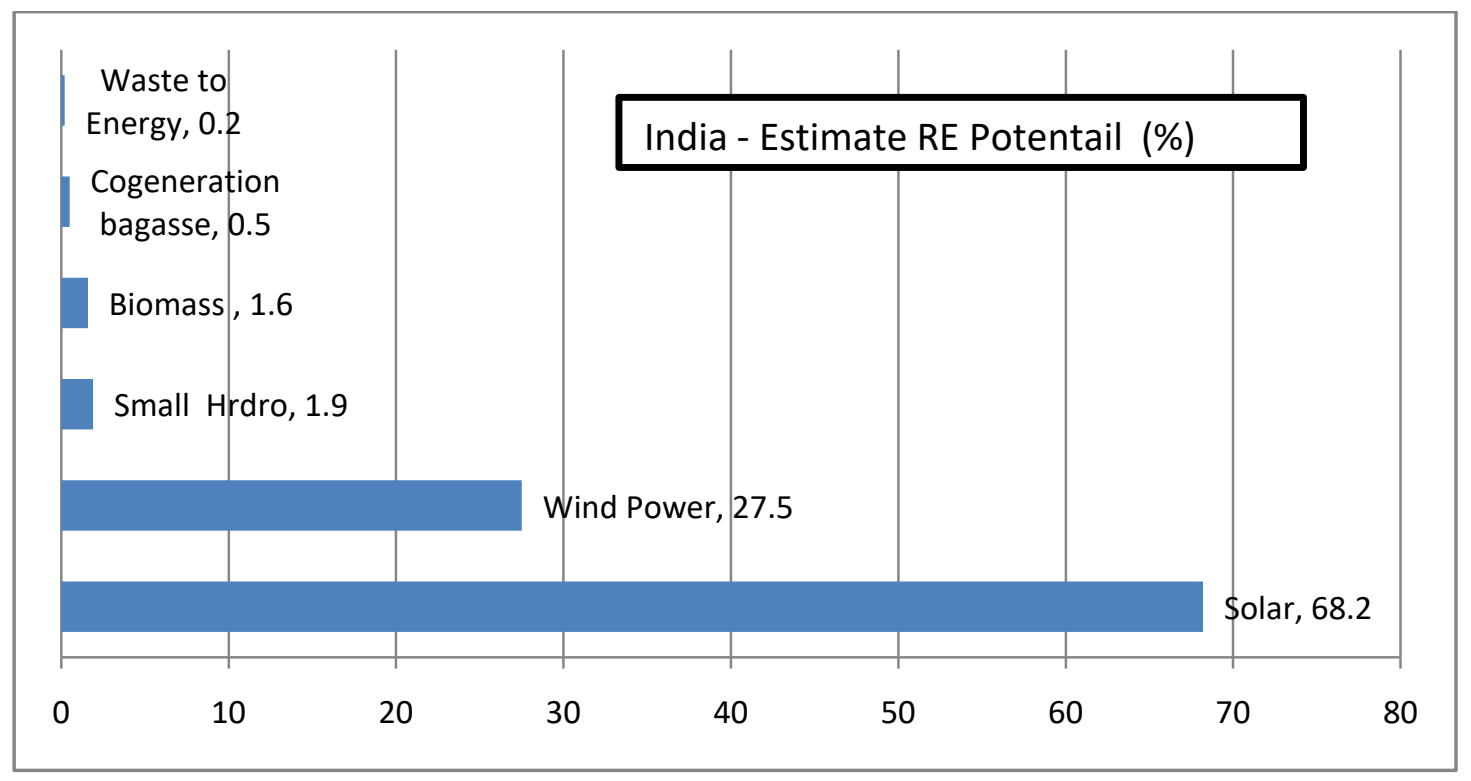

Figure 3: INDIA Renewable Energy potential, 2021 [6]

Solar energy photovoltaic (PV) and solar thermal are two points of interest but have restrictions depending on their accessibility, activity, and technology. So far many generations of solar cells have discovered, but their practical efficiency still lies low roughly 20-30\% and however leaves a lot of scope for upgradations. This low efficiency is due to various losses, occurs due to physical phenomena such as spectrum absorption, sunlight reflection \& transmission, particle collision, etc. All these results occur in energy loss at various stages of wave-particle interactions. This is known as Shockley-Quisser limit, a solar cell external and internal quantum efficiency limits [13]. In addition to this various environmental factors like temperature, spectral distribution, and resistive load also influence charge carrier generation and conduction, hence the efficiency of the solar cells.

In addition to this, Solar photovoltaic systems require a good fraction of land to catch incoming solar radiations, which in turn reduces land for plantations. These solar plants also disturb incoming solar radiation, thereby affect cultivations [1]. The land area requirements for both energy and food supply depend on consumption rate and also depend on various other factors like population density, weather conditions, etc. India has a high population density and mostly depends on agriculture for food and livelihood, economic prosperity. This indicates that the growth of agriculture can enhance economic growth [4].

The various Agri-energy innovative model has been suggested for generating Agri-energy, one of the sustainable solutions is solar energy. Much work has been done in this direction and suggested the use of solar energy for various agriculture-related tasks like drying, pump operation, harvesting, etc. Various solar panel designs are also designed to improve the efficiency of commercial solar energy. Recently few 
solar photovoltaic-thermal (PV/T) designs are available in the market that captures light and heat together. All these reduce the impact of issues like spectrum loss, incident angle sun tracking systems, and others. Recent solar industry professionals suggested the Co-utilization of Solar radiation, for electricity generation and agriculture production. Such dual agri-voltaic projects are complex and require some extra changes to increase the production of both.

Various problems, that reduces the efficiency of the solar cells has been discussed in previous sections and various work has been done in this direction, like multi-junction solar cells for spectrum loss problem, thermionic converters for reducing thermalization losses, anti-reflection coating to reduce reflection losses, aluminum nitride layers for recombination losses, plasmonic effect using nanoparticles for light scattering and many more. The human and plant both use solar light for their benefits, does plant also used much such modification described above for better photosynthesis efficiency.

\section{SOLAR TREE AS AN ALTERNATIVE}

Various investigators have studied similarities between photoelectric effect and photocell and suggested the use of plant and leaf geometry for solar cell efficiency enhancement. Their standing against various extreme conditions also motives investigators. Different changes have been done in traditional solar flat models to improve solar energy absorption, for example, low absorption coefficient, heat loss, solar oriented model, and so forth, As a sun oriented cell and a tree is that both attempt to catch the most solar spectrum with least heat loss. The spiral arrangement of outwards braches on the trunk will normally follow a phyllotaxic arrangement. In this arrangement Fibonacci ratios, spiral turn around trunk $\mathrm{n}$ to the number of branches p play an important role. On this basis, solar trees have Fibonacci ratios such as $1 / 3$, $2 / 5,3 / 8$, and $5 / 13$ from bottom to top. This ratio will decide the angle between the branches and affect efficiency. It is found that the secrets of such outputs are based on their large numbers of absorbers in a different direction with curved surface geometry.

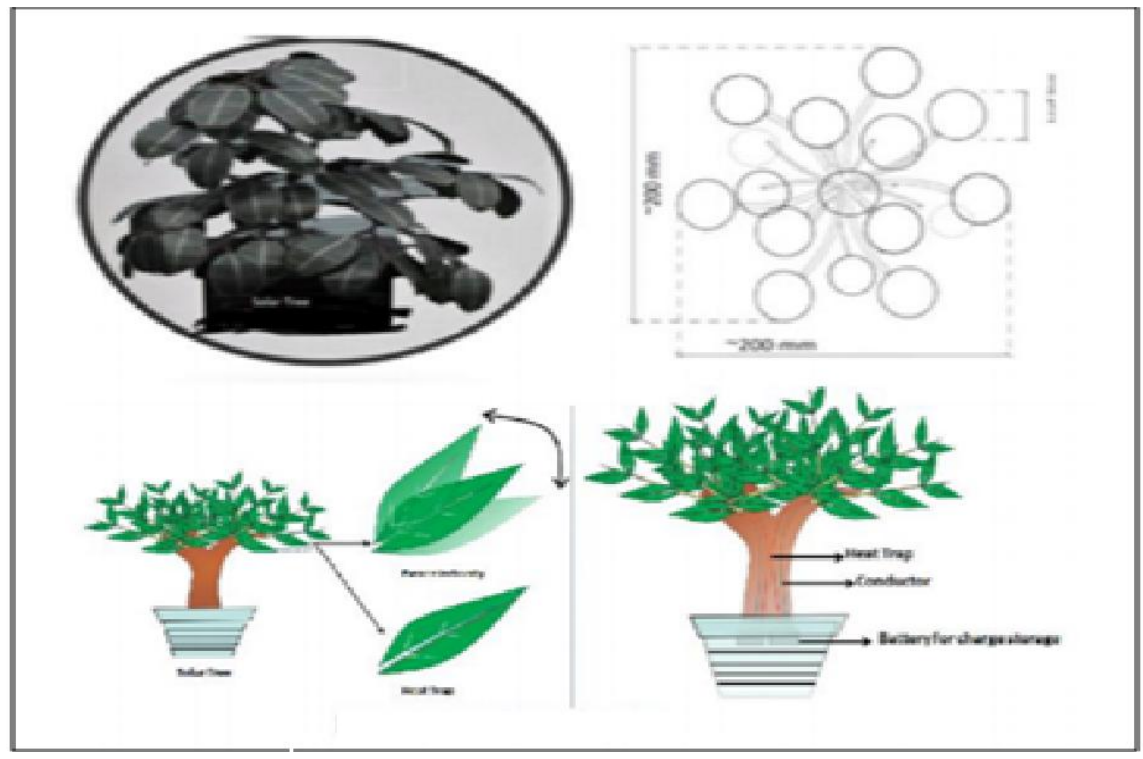

Figure 4: Solar Tree design [6] 
On the comparisons of the tree and solar cell, studies show that solar cell conversion processes are associated with multiple-stage energy loss. It can utilize tree-like models to enhanced solar sensitivity and further efficiency improvements. So alteration, in design and materials in solar cells provide a scope of improvement. The use of thermionic converters helps in reducing thermalization losses, thereby leading to enhanced sensitivity. Few such popular models are shown in figure 4, The solar tree will work as an independent unit that produces inexperienced strength and presents a vicinity of remedy and electricity for an extensive range of services.

As a guideline, an area of approx. 5-6 acres is required for a 1 MW Power Pressure PV module Framework, while a solar tree will only cover 1-5 percent of the area. The variable parameters make less space necessary and the installation cost can be reduced. The multi-angle orientation parameter of the solar tree panels gives a potential to absorb higher sunlight intensity, resulting in higher output energy in comparison to the traditional solar farm which is oriented in one direction. It may even be closed anyway because of heavy storms that affect the main pole/trunk, to withstand the wind pressure. The panels are naturally facing the Sun at the required angle so that maximum solar energy can be collected during the day. The unique technology, flexibly connected panels that can be rotated as we like, and offer a range of wind energy harvesting during the day and night.

The implementation of a solar tree requires a steel trunk with metallic branches. Various such design has been implemented in a residential zone. CSIR-CMERI India has installed the World's Largest Solar Tree, in Durgapur with an annual capacity of 12,000-14,000 units. Power generated depends on the number of solar panels, their capacity, and the quality of the panel. The installation cost varies accordingly to solar tree size and power requirement.

\section{ENERGY MODEL FOR SUSTAINABLE FARMING}

Sustainable use of natural resources like land, vegetation, and water is the crucial one, in the scenario of increasing demand pressure. Energy is the main element of sustainable farming and Solar energy is found to be the most sustainable energy solution. Sunlight radiation interaction depends on the object it falls, like photosynthesis in plants and photovoltaic in the solar cell. The agri-voltaic project is complex and requires added layers of intricacy in a design. To accommodate the dual-use impact of solar light, need balance coordination in resources. The suggested layout will address prime issues like food and energy in such a way as to have high-value crop production and efficient solar energy off-grid system. Efficient utilization needs to address the proper utilization of the same land. Therefore key issues are to the utilization of area for cultivating agriculture produce under the solar panels.

Sustainability energy design: Such an energy solution requires circulation of energy and mass in a controlled way so that no dependence on external resources. Few such factors are :

- Food Production / Photosynthesis: No influences to solar light and moist humid soil nature.

- Water usage efficiency: limited water resources for society, so need efficient management.

- Zero discharge process: Postharvest residues recycle management ( Energy Loss )

- Dust removal: Dust affects Plantation/panel efficiency, also pollutants (Efficient dust management) 
- Energy Resource: Quantity meet energy need and no external energy requirement

- Solar cell: Clean Energy generator, the huge energy potential

- Wind Power: Wind is a common field commodity and must be harness

- Thermal Generator: Technologies to capture extra heat, otherwise affect the environment

So the energy, agriculture \& food, water \& natural resources are some vital components of a sustainable society. The concept of solar trees help a lot in this regard, because,

- Solar is a clean renewable energy source and has no environmental effect energy All these

- Uses low agriculture land, so provide a large area for Agriculture with meeting energy demands

- It helps in low waste production, others huge waste products for generating agri-energy

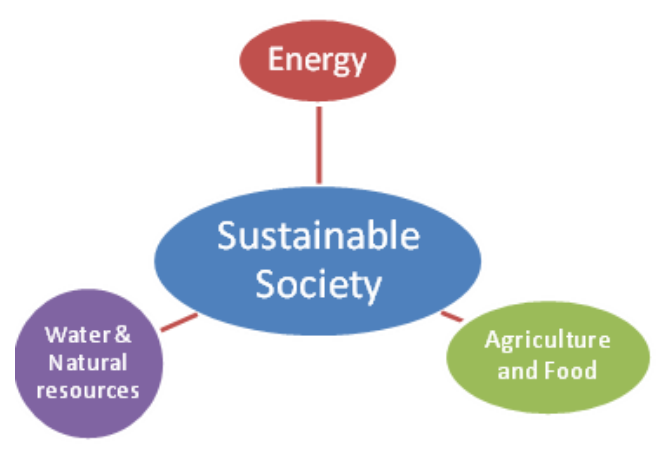

\section{AGRI-ENERGY: SOLAR TREE DESIGN}

From the section, it is clear that minimum space utilization for energy generation will increase food productivity. The unique characteristics of the solar tree-like height, multi-angle orientation parameters, etc make its fewer space requirements. It requires only about $1 \%$ of land area in comparison to power generation from the general PV panel. Its multi-angle orientation help in collecting maximum solar light in the daytime. The implantation of the solar tree is subjected to climate conditions and the crop pattern of the field. These factors decided the height of the tree and installation location. The boundary of the field is one of the suitable places for the same.

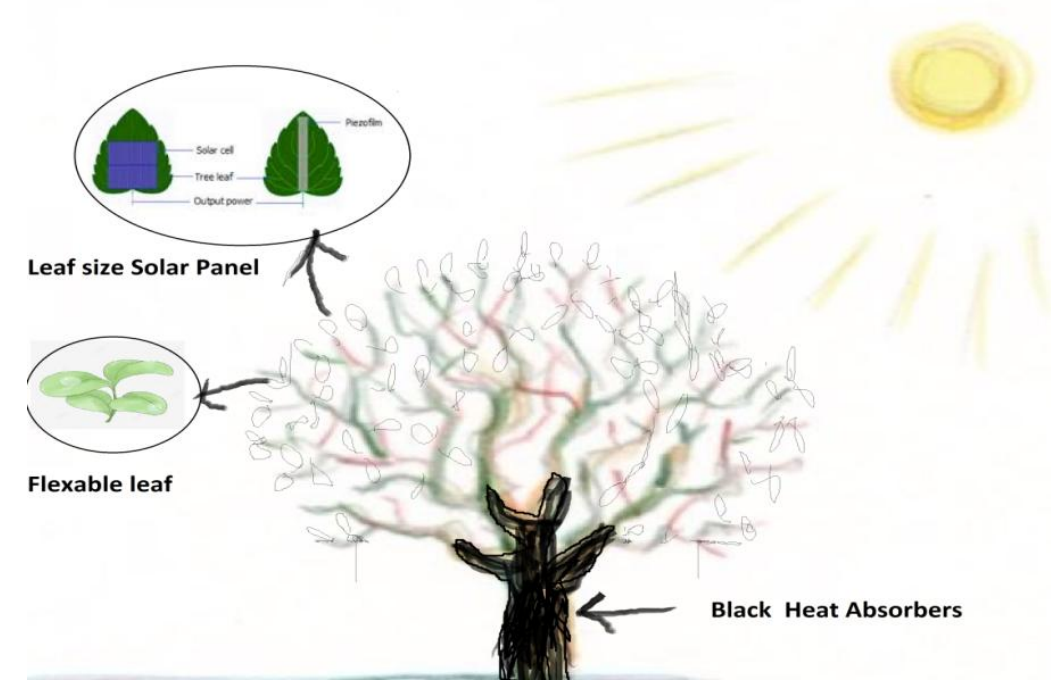

Figure 5: Flexible Solar Tree design

The installation of a solar tree depends on various geographical factors, tree design, and numbers. The solar tree shape and size design under available land. The power requirement will decide no of the tree. 
We proposed some modifications like flexible solar leaves, flexible branches, and black trunk to capture wind energy, piezoelectric energy, and blackbody heat absorber. The wind pressure can also be locked anywhere due to heavy storms affecting the principal pole/trunk. The specification in the fields includes maximum exposure to solar radiation, maximum wind, and heat for maximum profit. So solar trees require less land requirement, efficient energy generators, another associated energy harvesting, that work through day and night.

\section{Energy Design \& Analysis}

The installation of a solar tree of small size panel will be the better option. These can be installed on field boundaries or one of the boundaries affecting agricultural output. Such small trees are cheaper, can harness another form of energy, and can stand against weather conditions. Such energy use not only reduces environmental pollution but also has a space for harvesting another form of energy. This other form of energy includes another natural source like wind, biomass-based electric generator, and thermal generator

\section{Energy Generated $=$ Solar Energy + Wind Energy + Thermal Energy + Piezoelectric Energy}

in addition to Biomass and agriculture energy

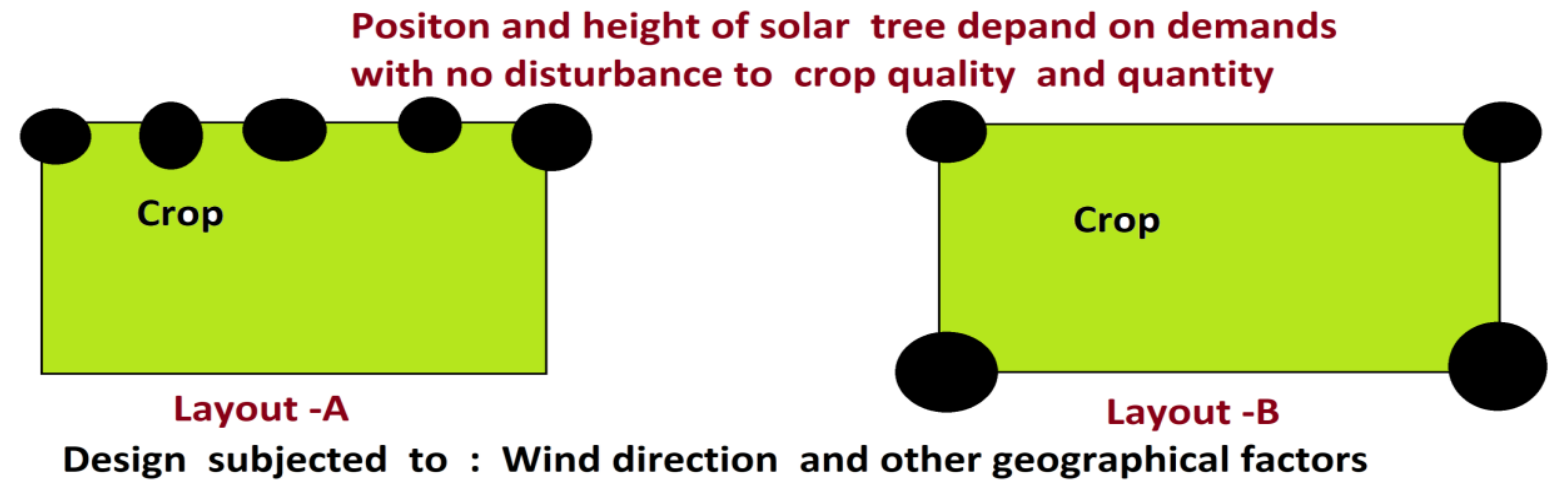

Figure 6: Agriculture Field Design for Solar Tree Installation

A smart energy controller will channelized energy flow and synchronized various energy inputs. This also helps minimize energy loss, which generally occurs in electrical transmission or leakage. A high-quality capable and minimum path with storage will enhance efficiency. The smart controller equipped with artificial intelligence can do better management; this will relegate energy to meet various Agri-Energy requirements, from simple irrigation and heating to crop moisture management. 


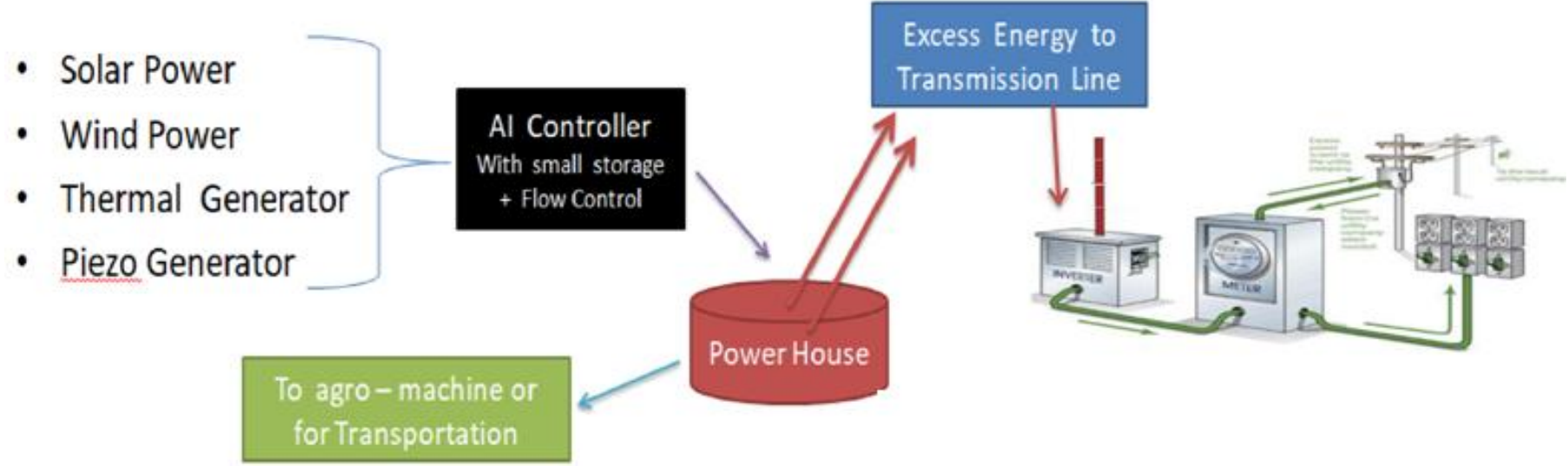

Figure 7: AI controller for harvesting Solar and other RE design,

The combination of all these approaches not only minimizes the energy dissipation but also gives a multirenewable energy harvesting option combination. Our proposed model uses various renewable energy resources like conversion of heat to usable energy, spectrum gain, and utilization of wind power. In this situation, solar tree energy is added by other sources of power generation. This model also uses waste heat, energy from waste heat through thermocouples.

So Artificial Intelligent equipped Controller can synchronize the energy input and minimize any loss. Other adjustments like minimum cable path, high-quality cable, high-quality storage, will increase efficiency, reduce loss, and efficient control.

More attention is needed to address the costs of initial renewable energy investment, the failure to build and maintain technical skills, the lack of societal knowledge on the benefits of renewable energy from these solar trees, and the lack of incentives to encourage farmers and stakeholders in the agricultural area. State legislation that promotes solar tree energy generation should be adopted in the agricultural sector. Business-friendly legislation should be adopted. An innovative public benefits fund is also essential to leverage private investment in the agricultural sector's renewable energy projects. In the agricultural business, it should be encouraged to install small-scale energy capacity. It will help to fight climate change and improve the viability of businesses. Through partnerships between governments and the private sector and international collaboration among nations, these problems can be resolved effectively. In short, solar tree guarantees energy demand in agriculture while safeguarding the environment and enhancing energy efficiency, which reduces energy and finance. energy efficiency.

\section{CONCLUSIONS AND FUTURE REMARKS}

In agriculture, the use of renewable energy can resolve different challenges associated with the use of fossil fuels, since it involves low or no production or dependence on imported fuel. There are, therefore, huge profits from the application of such sun trees in agriculture. Solar tree-based renewable technology has an enormous potential to meet different energy needs and agri-energy demands. It is a sustainable 
solution for energy because it reduces dependence on agricultural fossil fuels, lower operating costs, fewer effects on agricultural space, and a long-lasting potential for energy. For the improvement of efficiency and 24x7 energy use in agriculture, other renewable energy sources such as wind, thermal, and biomass were included. The solar tree provides agriculturists with a long-term source of income, as well as harvesting energy without affecting crops.

\section{ACKNOWLEDGMENT}

Special thanks to Late Prof. Vinay Gupta for their guidance and supports.

\section{REFERENCES}

1. A., and Ferard Y. 2011, " Combining Solar Photovoltaic Panels and Food Crops for Optimising Land Use: Towards New Agrivoltaic Schemes,” Renewable Energy 36 ( 10 ), pp. 2725 - 2732

2. Alexis S. Pascaris, Chelsea Schelly, Laurie Burnham, Joshua M. Pearce, Integrating solar energy with agriculture: Industry perspectives on the market, community, and socio-political dimensions of Agri-Voltaics, Energy Research Social Science, Volume 75, 2021, 102023,

3. Energy Statistics 2017-2019, Central Statistics Office Ministry Of Statistics And Programme Implementation GovernMent Of India New Delhi

4. FAO. 2000b. The Energy and Agriculture Nexus. Environment and Natural Resources Working Paper No. 4. Food and Agriculture Organization of the United Nations, Rome.

5. ISA, 2016, "Framework Agreement on the Establishment of the International Solar Alliance (ISA)," International Solar Alliance, accessed Dec. 20, 2017,

6. J Balaji, PN Rao SS Rao, Solar Tree with Different Installation Positions of Photovoltaic Module-Part, Journal of Green Engineering, 2020, Volume-10, Issue-9, September 2020.

7. Kumar M, "TAMING WASTE VIA LAWS OF PHYSICS " in International Journal of Sustainable Energy and Environmental Research, 2014, 3(3): 164-170

8. Kumar M. and Parashar D., PIEZOELECTRICITY: A NEW WAY OF TAMING ENERGY ” by in “ Physics Education" 2014, Volume 30, Issue 4, Article Number: 6.

9. Kumar M, Kumar K."TRAFFIC-DRIVEN WIND ENERGY GENERATOR ", Technology Letters, Vol.3 No.1 (2016) 10-13 (ISSN: 2348-8131).

10. Kumar M, Kumar K., and Rana R., "WIND ENERGY GENERATION FROM TRAFFIC MOVEMENT " DU Journal of Undergraduate Research and Innovation Volume 2, Issue 1 pp 116-120, 2016 ( ISSN 2395-2334 ).

11. M Kumar, S Kumar, SK Singh - 2021, Waste management by "waste to energy" initiatives in India,, International journal of sustainable energy and environmental research, 10(2), 58-68.

12. M. Kumar, S.K.Singh , "Taming waste via laws of physics", International Journal of Sustainable Energy and Environmental Research, 2014, 3(3): 164-170, 2312-5764.

13. M Kumar, JP Kesari, L Rana, Flexible Solar Power Tree-A Concept, Journal of Engineering Technology and Applied Sciences (2020), Vol 5(2): pp -217-221

14. Rajiv Singh, Neelam Rawat and Dr. Ratnesh Srivastava, Performance Evaluation of a Solar Tree Design and a Fixed Solar Panel for Effective Solar Power Harnessing, International Journal of Applied Engineering Research ISSN 0973 4562 Volume 14, Number 11 (2019) pp. 2616-2621

15. Nonhebel S., 2005 , "Renewable Energy and Food Supply: Will There Be Enough Land?," Renewable Sustainable Energy Rev. , 9 ( 2 ), pp. 191-201

16. Singh SK, Kumar M., S. Kumar, (2020), Plasma technology as waste to energy: a review, International Journal of Advanced Research, 8(i2):2320-5407. 